\title{
MiR-500a-3p inhibits cell proliferation and invasion by targeting lymphocyte antigen 6 complex locus K (LY6K) in human non-small cell lung cancer
}

\author{
X. H. LIAO ${ }^{1}$, Z. XIE ${ }^{1}$, C. N. GUAN ${ }^{2, *}$ \\ ${ }^{1}$ Department of Oncology, The First Affiliated Hospital, Guangdong Medical University, Zhanjiang, China; ${ }^{2}$ Cancer Center, Guangdong Medical \\ University, Dongguan, China \\ *Correspondence: guanchengnong145@163.com
}

Received May 16, 2017 / Accepted December 8, 2017

\begin{abstract}
LY6K (lymphocyte antigen 6 complex locus K) is an anti-gene in non-small cell lung cancer (NSCLC) and miR-500a-3p promotes the progression of cancers. Evidence shows that increased miR-500a-3p caused LY6K suppression. Herein, we hypothesize that miR-500a-3p takes part in the progression of NSCLC through targeting LY6K. miR-500a-3p expression levels in NSCLC specimens and cell lines were detected by quantitative real-time PCR (qRT-PCR). The mRNA and protein expression levels of LY6K in NSCLC specimens and cell lines were examined by qRT-PCR, immunohistochemistry and western blotting. Dual-luciferase reporter assay assessed miR-500a-3p binding to the LY6K gene. The functions of miR-500a-3p and LY6K in proliferation/invasion and lung metastasis formation were assessed by CCK8, Transwell assay and subcutaneous tumor model in nude mice, respectively. Statistical analysis explored the clinical correlation between miR-500a-3p/LY6K expression and clinical-pathological features. While miR-500a-3p was substantially decreased in NSCLC tissues and cell lines. LY6K protein and mRNA level expressions were increased in NSCLC patients. Clinical analysis indicated that miR-500a-3p and LY6K were related to tumor differentiation, lymph node metastasis and TNM staging in NSCLC patients. MiR-500a-3p suppresses cell proliferation, invasion and metastasis formation in vivo by targeting the LY6K. miR-500a-3p acts as a tumor suppressor in NSCLC partly by down-regulating LY6K expression, and this suggests it is a potential therapeutic target for NSCLC intervention.
\end{abstract}

Key words: LY6K, miR-500a-3p, non-small cell lung cancer, NSCLC, invasion, proliferation

Lung cancer is the most common cause of cancer-related mortality worldwide [1]. Despite significant progress in cancer therapy over the past decades, non-small cell lung cancer (NSCLC) remains a major threat with low 5-year overall survival rate to $15 \%$ [2]. NSCLC, together with adenocarcinoma (AC), squamous cell carcinoma (SCC), large cell carcinoma and broncho-alveolar carcinomas (BAC), is the principal form of lung cancer [3, 4]. Distant metastases are responsible for the failure of lung cancer therapy and its poor prognosis, and detailed knowledge of the underlying mechanism of NSCLC development at the molecular level is therefore required.

Lymphocyte antigen 6 complex locus $\mathrm{K}(L Y 6 K)$ is part of theLy-6/urokinase-type plasminogen activator receptor (upper) super-family and a novel cancer-testis antigen [5]. Surprisingly, it has been shown that over-expression of $L Y 6 \mathrm{~K}$ relates to poor prognosis in patients with NSCLC and plays a promotive role in the proliferation of NSCLC cells while inhibition of its expression by siRNA effectively stopped growth of $L Y 6 K$-poxitive cancer cells [6]. Therefore, targeting LY6K epigenetic modification is considered a prospective cancer therapeutic strategy.

MicroRNAs (miRNAs) are non-coding RNAs that regulate gene expression at the post-transcription level [7]. Many studies indicate that they are often deregulated in cancers and correlate with proliferation, apoptosis, invasion, migration, drug resistance and metastasis [8-12]. It has been reported that miRNAs are also involved in NSCLC proliferation and invasion. Examples include promoter miR-1271 by down-regulation of HOXA5 [13] and inhibitor miR-342-3p through repression of RAP2B [14]. Although MiR-500a-3p, combined with SNPs rs3732360, rs1054190 and rs1054191, correlates with poor response to therapy in patients with breast cancer and is down-regulated in doxorubicin treated cells [15], in ERa-negative breast cancer cells it can be increased by ERa re-expression, directly leading to inhibition of $L Y 6 K$ expression; and LY6K mRNA and protein expression is significantly reduced by ectopic miR-500a-3p 
[16]. Therefore, we hypothesize that miR-500a-3p can target $L Y 6 K$ and thus participate in the development of NSCLC. We conducted our study to verify this hypothesis and to determine the precise interaction between miR-500a-3p and LY6K and their roles in NSCLC progression.

We recognized the expression of miR-500a-3p and LY6K in human NSCLC tissues and therefore studied their correlation with the clinical-pathological features of NSCLC. We validated the correlation between miR-500a-3p and LY6K in NSCLC cell lines using Luciferase assay, Western blot analysis, CCK8 and Transwell assay. For further verification of our findings from the above experiments, we performed an in vivo experiment with a xenograft mouse model. The study aims to establish the exact role of miR-500a-3p and also the interaction between miR-500a-3p and LY6K in NSCLC progression.

\section{Patients and methods}

Ethical statement. Our study was performed in accordance with the approval and guidelines provided by Medicine Ethics Review Committee at First Affiliated Hospital of Guangdong Medical University. All participants signed consent forms.

Patients and specimens. Tumor tissue $(n=48)$ and paired adjacent normal tissue $(n=48)$ were harvested from patients with NSCLC undergoing surgical resection in First Affiliated Hospital of Guang dong Medical University between January 2013 and January 2015. All patients were diagnosed with squamous cell carcinoma, adenocarcinoma, large cell carcinoma or small bronchial alveolar carcinoma by pathologists and the tissues were collected before surgery, chemotherapy or radiotherapy. Exclusions included patients with NSCLC who provided incomplete information with no preoperative findings for the T3 phase and M1 period and those who suffered vascular disease, diabetes, liver and kidney disease or had other surgical history. Clinical-pathological data were recorded, including age, gender, tumor site, tumor differentiation, primary tumor lesions, regional lymph node metastasis, TNM stage and histological information (30 with Adenocarcinoma, 18 with Squamous and others). Both tumor tissues and paired adjacent normal tissues were allocated to two groups; one immediately frozen in liquid nitrogen and stored at $-80^{\circ} \mathrm{C}$ until RNA extraction and the other stored in formalin for pathology analysis.

Real time quantitative PCR (qRT-PCR). Total RNA was extracted by Trizol (Invitrogen) kit according to the manufacturer's instructions. The expression of miRNAs was measured by TaqMan stem-loop RT-PCR method from Applied Biosystems (Foster City, CA, USA). Approximately $10 \mathrm{ng}$ of total RNA was reverse-transcribed according to the MicroRNA Reverse Transcription kit and specific stem-loop primer was performed to detect LY6K. (Applied Biosystems, Foster City, CA). SYBR green RT-PCR (TaKaRa). The sequences are as follows: forward: 5'-AGCCCATGCCCTTCTTTTAC-3' and reverse: 5'-CCAGCCACAGCCCACCACAG-3'. All RT-PCR experiments were performed on the GeneAmp ${ }^{\circledR}$ PCR System 9700 (Applied Biosystems, Foster City, CA) and all RT-PCR assays were carried out by 7300 Real-Time PCR System with SDS RQ Study software (Applied Biosystems). Glyceraldehyde-3-phosphate dehydrogenase (GAPDH) and U6 snRNA were used as the endogenous control for mRNA and miRNA expression, and the difference between the expression of the target gene of the experimental group and the control group in each sample was indicated as $\Delta \Delta \mathrm{CT}=\Delta \mathrm{Ct}$ experimental group $\Delta \mathrm{Ct}_{\text {control group }}, \Delta \mathrm{Ct}=\mathrm{Ct}_{\text {target }}-\mathrm{Ct}_{\text {endogenous control }}$.

Immuno-histochemical analysis. Immuno-histochemical staining for $\operatorname{LY6K}$ (1:250, d-Aldrich, St. Louis, MO, USA) was performed on tissue microarray blocks with $3.0 \mathrm{~mm}$ core. Briefly, tissue microarray was arrayed at 1 core/case. The antigen retrieval procedure was performed in a microwave oven for 20 minutes in ph6.0 sodium citrate buffer. The scoring for $L Y 6 \mathrm{~K}$ immuno-staining was performed by two pathologists by consensus without knowledge of clinicalpathological information. Immuno-histochemical results were assessed according to the reported criteria and protein expression was evaluated according to the frequency of positive staining in the cytoplasm or nucleus of cancer cells. Ten different horizons were randomly selected for doubleblind counting at high magnification. One hundred cells were assessed for each high-power field. The expression was classified positive $(+)$ when there were more than $50 \%$ positively stained cells and the remainder negative $(-)$.

Cell culture. H226 (squamous cell carcinoma), H358 (bronchial alveolar carcinoma), A549 (adenocarcinoma) and L9981 (human lung large cell lung cancer) cell lines were used (Shanghai Institute of Biochemistry, Shanghai, China). All cells lines were seeded in 6 -well plates at $5 \times 10^{4}$ cells/ml density and cultured in RPMI-1640 medium with $10 \%$ imported fetal bovine serum (hy-clone, USA), $100 \mathrm{U} /$ $\mathrm{ml}$ penicillin, and $100 \mathrm{mg} / \mathrm{L}$ streptomycin. The cells were cultured at $37^{\circ} \mathrm{C}$ in saturated humidity and $5 \%$ carbon dioxide. During cell passage, cells were trypsinized with $0.125 \%$ trypsin (including $0.1 \%$ EDTA, Gibco, USA). When the cell gap increased, trypsin solution was abandoned. Medium dispersed suspended cells were then cultured.

Cell transfection. H226 and H358 cells in the logarithmic phase of growth were digested and counted, then seeded to a 6 -well plate at a density of $2 \times 10^{5}$ cells/well. The cells were then transfected using the lipofectamine 2000 kit (Invitrogen, Carlsbad, CA, USA), by $50 \mathrm{nmol} / \mathrm{L}$ LY6K siRNA, miRNA mimics or inhibitors and their respective negative controls. The transfected cells were incubated at $37^{\circ} \mathrm{C}$ with $5 \% \mathrm{CO}_{2}$ for 4 to 6 hours and then continued to be cultured with 1640 medium containing 10\% FBS for another 24 to 48 hours. All transfection sequences were provided by Shanghai Sangon Biotech Co., Ltd (Shanghai, China).

Western blotting. Proteins were isolated using the nucleospin ${ }^{\circledR}$ RNA/Protein kit (MACHEREY-NAGEL). Protein content was measured with Bicinchoninic acid 
Solution (Sigma, USA) and Copper (II) sulfate solution (Sigma, USA). Proteins were separated on $12 \%$ or $8 \%$ SDS-PAGE gel and Western blotting Assay was performed with SDS-PAGE gels. The primary antibodies were diluted at $1: 1000$ in $1 \%$ skim milk in PBST. Primary antibodies used in this study were LY6K (Santa Cruz Biotechnology, USA) and $\beta$-actin (Bethyl Laboratories, US). $\beta$-actin was used as a loading control. Immunoreactive proteins were detected by horseradish peroxidase-conjugated secondary antibodies and the enhanced chemiluminescence reagent, ezwestlumi plus (ATTO, JAPAN).

Dual-luciferase reporter assay. Human LY6K 3'UTR which included the predicted miR-500a-3p seed sequences were in psicheck ${ }^{\mathrm{TM}}-2$ vector (Promega, USA) using the In-fusion ${ }^{\otimes D}$ Cloning Kit (Clontech Laboratories, USA). The seed sequence for miR-500a-3p on LY6K 3'UTR was mutated by the quick-change II XL Site-Directed Mutagenesis Kit (Agilent Technologies, USA). We transfected HEK293T cells with luciferase reporter containing the LY6K 3'UTR variants and 30nm of miR-500a-3p mimics or negative control miRNA with Lipofectamin 2000 (Invitrogen, USA). After 48 hours, all experimental cells were lysed and measured by Dual Luciferase Assay System (Promega, USA).

Cell proliferation assay. At cell confluence of $80 \%$, cells were rinsed with PBS twice and digested in a single cell suspension with $0.25 \%$ trypsin. After counting, the cells were seeded in a 96-well plate at a density of $3 \sim 6 \times 10^{3}$ cells/well and a volume of $200 \mu \mathrm{l} /$ well. Each well was repeated 6 times. The plate was removed from the incubator after 24, 48 and 72 hours cultivation and $10 \mu \mathrm{l} /$ well CCK8 was added (Dojindo, JAPAN). The cells were then cultivated for a further 2 hours and the optical density (OD) of each well was detected at $450 \mathrm{~nm}$ using a spectrophotometric plate reader. Each experiment was in triplicate and the cell survival curve was drawn based on the time on the abscissa and OD on the ordinate.

Transwell assay. Matrigel (Corning, USA) was thawed overnight at $4{ }^{\circ} \mathrm{C}$ and $30 \mu \mathrm{l}$ diluted with serum-free 1640 medium (1:3). Matrigel was added to the upper chamber of every transwell chamber 3 times $(15,7.5$ and $7.5 \mu \mathrm{l})$ at an interval of 10 minutes and evenly plated on the membrane to cover all micro-wells in the bottom of the upper chamber. Cells were suspended and seeded to the upper chamber of Transwell after 48 hours transfection, (Corning, USA). A total of $0.5 \mathrm{ml} 1640$ medium containing 10\% FBS was added to the lower chamber of a 24 -well plate. After 48 hours culture at $37^{\circ} \mathrm{C}$ with $5 \% \mathrm{CO}_{2}$, the non-migrating cells in the upper chamber were slowly removed and membranes were fixed in $95 \%$ ethanol for 15 to $20 \mathrm{~min}$ and stained with crystal violet solution for 10 minutes. Cells were counted after rinsing and photographed at high magnification by inverted microscope. The collected data consisted of the means of the number of cells in 5 fields of visions. The number of cells which migrated through the Matrigel was regarded as the evaluation index of cell invasion.
Animal model. For the experimental metastasis mouse xenograft model, H226 and H358 cells transfected with miR-500a-3p inhibitors or LY6K siRNA, or the negative control sequences were suspended in $100 \mu$ l of phosphatebuffered saline by injecting them subcutaneously into the right subcutaneous anterior axillary of BALB/c nude mice (4-5 weeks old females - Beijing HFK Bioscience Co., Ltd, China). Each tumor cell sub-line was injected $2 \times 10^{6}$ per mouse. The nude mice were randomly divided into the following three groups ( $\mathrm{n}=4$ each): Inhibitors group, Inhibitors + LY6K siRNA group and Control inhibitors group. Tumor volume (V) was monitored every 3 days after the first day of agomir injection by measuring the tumor length (L) and width $(\mathrm{W})$ with a vernier caliper and calculated using the formula $\mathrm{V}=0.5 \times \mathrm{L} \times \mathrm{W}^{2}$. The animals were sacrificed 48 hours after the last injection and the tumor tissues were resected. All mice were manipulated and housed according to protocols approved by the First Affiliated Hospital of Guangdong Medical University Experimental Animal Care Commission.

Statistical analysis. Experiments were replicated at least three times in this study, and data was presented by mean \pm standard deviation (SD) ( $x \pm s$ ). All statistical analyses were by Graphpad Prism 5.0 (Graphpad software, La Jolla, CA, USA) or SPSS 20.0 software (SPSS, Inc, Chicago, USA). Comparison between two groups was tested by Student's t-test and those between three or more groups were analyzed by one-way analysis of variance (ANOVA). The count materials among groups were compared by 2 -way test with $\mathrm{p}<0.05$ significance.

\section{Results}

Reduction of miR-500a-3p in NSCLC tissues and relationship to clinical-pathological features. The qRT-PCR assay established that the NSCLC tissue had significantly lower miR-500a-3p expression compared to paired adjacent normal tissue. $(\mathrm{p}<0.001$, Figure 1$)$ Table 1 shows that miR-500a-3p expression closely correlates with tumor differentiation, lymph node metastasis and TNM staging (all $\mathrm{p}<0.001)$ but had no significant correlation with age $(\mathrm{p}=0.15)$, sex $(p=0.07)$, location $(p=0.82)$, primary lesion $(p=0.19)$ or pathologic diagnosis $(\mathrm{p}=0.16)$.

LY6K expression in NSCLC tissues and its relation to the clinical-pathological features. The qRT-PCR assay detected that LY6K mRNA significantly increased in NSCLC tissue compared to paired adjacent normal tissue (Figure $2 \mathrm{~A}, \mathrm{p}<0.001)$. This contrasted sharply with the miR-500a-3p mRNA result. The immunohistochemistry assay depicted NSCLC LY6K stained a brownish-yellow color (Figure 2B). The relationship of LY6K in NSCLC to the clinical-pathological features is represented in Table 2; with significantly close correlation identified between $L Y 6 K$ expression and tumor differentiation $(p=0.02)$, lymph node metastasis $(p=0.02)$ and TNM staging $(\mathrm{p}<0.02)$. In contrast, no correlation was recorded between $L Y 6 K$ expression and age $(\mathrm{p}=0.08)$, sex 


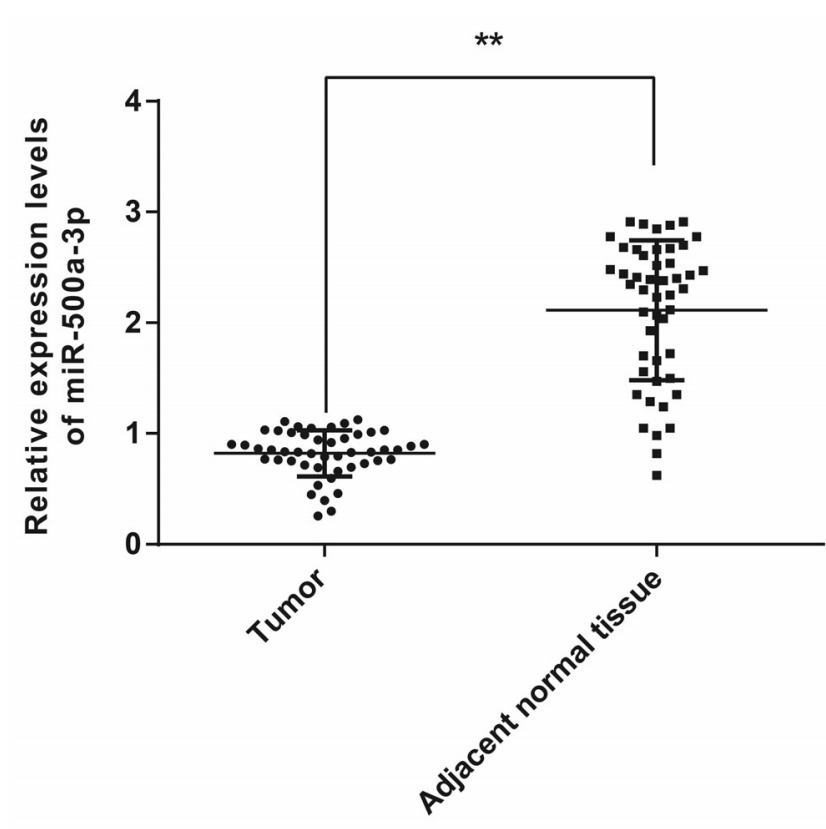

Figure 1. Expression of miR-500a-3p in tumor tissues and paired adjacent normal tissues. The results were normalized to U6 expression and expressed as fold change in tumor compared to paired adjacent normal tissues. Total RNA extracted from 48 pairs of matched NSCLC samples which used qRT-PCR analysis of mRNA expression. ${ }^{* *} \mathrm{p}<0.001$.

$(\mathrm{p}=0.23)$, location $(\mathrm{p}=0.65)$, primary lesion $(\mathrm{p}=0.52)$ or pathologic diagnosis $(\mathrm{p}=0.58)$.

MiR-500a-3p negatively correlates with $L Y 6 K$ in NSCLC. In confirming that $L Y 6 K$ could be a target for miR-500a-3p, Pearson's correlation test detected their highly negative correlation in NSCLC tissue at $\mathrm{p}<0.001$ (Figure 3A). The immunohistochemistry assay then highlighted that LY6K-positive tissues had a significantly lower miR-500a-3p expression than LY6K-negative tissue; thus suggesting correlation between $L Y 6 K$ and miR-500a-3p $(\mathrm{p}<0.001$, Figure 3B, C).

Selection of NSCLC cell lines with stable miR-500a-3p expression. The miRNA-500a-3p expression in NSCLC cell lines was measured by qRT-PCR assay and A549 had the lowest miR-500a-3p expression of the four H226, H358, A549 and L9981 cell lines (Figure 4). The single factor analysis of variance also provided significant difference, where the miR-500a-3p expression in A549 was significantly lower than that in the H226 ( $<<0.01), H 358(p=0.02)$ and L9981 $(\mathrm{p}<0.001)$ cell lines, While the L9981cell line demonstrated the strongest expression of miR-500a-3p, the H226 and H358 cell lines provided more stable miR-500a-3p expression and are therefore more suitable for further experimentation.

MiR-500a-3p directly targets at sites on LY6K-3' UTR. Luciferase reporter gene plasmids containing wt LY6K-3' UTR or mut. LY6K-3' UTR (Figure 5A) were constructed
Table 1. The relationship between miR-500a-3p expression level and clinical pathological characteristics of NSCLC patients.

\begin{tabular}{|c|c|c|c|}
\hline Clinical characteristics & No. of cases & $\begin{array}{c}\text { miR-500a-3p } \\
\text { expression level }\end{array}$ & p-value \\
\hline Age & & & 0.15 \\
\hline$<60$ & 26 & $0.861 \pm 0.155$ & \\
\hline$\geq 60$ & 22 & $0.774 \pm 0.252$ & \\
\hline Gender & & & 0.07 \\
\hline Male & 35 & $0.787 \pm 0.223$ & \\
\hline Female & 13 & $0.911 \pm 0.128$ & \\
\hline Tumor site & & & 0.82 \\
\hline Left & 21 & $0.813 \pm 0.212$ & \\
\hline Right & 27 & $0.827 \pm 0.207$ & \\
\hline Tumor differentiation & & & $<0.001$ \\
\hline Low & 28 & $0.936 \pm 0.119$ & \\
\hline High/moderate & 20 & $0.660 \pm 0.199$ & \\
\hline Primary tumor lesions & & & 0.19 \\
\hline $\mathrm{T} 1$ & 40 & $0.835 \pm 0.214$ & \\
\hline $\mathrm{T} 2$ & 8 & $0.748 \pm 0.166$ & \\
\hline \multicolumn{2}{|c|}{ Regional lymph node metastasis } & & $<0.001$ \\
\hline $\mathrm{N} 0 / \mathrm{N} 1$ & 25 & $0.923 \pm 0.132$ & \\
\hline $\mathrm{N} 2 / \mathrm{N} 3$ & 23 & $0.710 \pm 0.220$ & \\
\hline TNM stage & & & $<0.001$ \\
\hline $\mathrm{I} / \mathrm{II}$ & 27 & $0.922 \pm 0.131$ & \\
\hline III/IV & 21 & $0.691 \pm 0.218$ & \\
\hline Histology & & & 0.16 \\
\hline Adenocarcinoma & 30 & $0.788 \pm 0.213$ & \\
\hline Squamous and others & 18 & $0.875 \pm 0.165$ & \\
\hline
\end{tabular}

NSCLC, non-small cell lung cancer; TNM, tumor, node, and metastasis

to examine the prediction that miR-500a-3p directly targets LY6K in LY6K-3' UTR at site 139-146 or site 611-618 (Figure 5A). In line with the co-transfection scheme, 293Tcell line was allocated into MT + mimics group (mut. plasmids + miR-500a-3p mimics), $\mathrm{MT}+\mathrm{NC}$ (mut. plasmids + negative controls), $\mathrm{WT}+$ mimics (wt plasmids + miR-500a-3p mimics) and WT + NC (wt plasmids + negative controls). The WT + mimics group presented significantly inhibited plasmid luciferase activity, while $\mathrm{MT}+$ mimics group registered no inhibition compared to the WT + NC group and MT + NC group (Figure 5B). These results infer that miR-500a-3p negatively regulates NSCLC $L Y 6 K \mathrm{mRNA}$ and protein.

We further examined $L Y 6 \mathrm{~K}$ mRNA and protein expression by qRT-PCR and Western blot assay in the H226 and H358 cell lines. The mimics group had significantly lower $L Y 6 K$ mRNA and protein expressions than the control group and the inhibitors group had significantly higher LY6K mRNA and protein expression (Figure 5C, D). All results therefore suggest that miR-500a-3p directly targets LY6K in LY6K-3' UTR at the predicated sites.

MiR-500a-3p targeting $L Y 6 K$ inhibits proliferation and invasion of NSCLC cells. We next reduced miR-500a-3p and silenced LY6K in H226 and H358 cell lines to estab- 


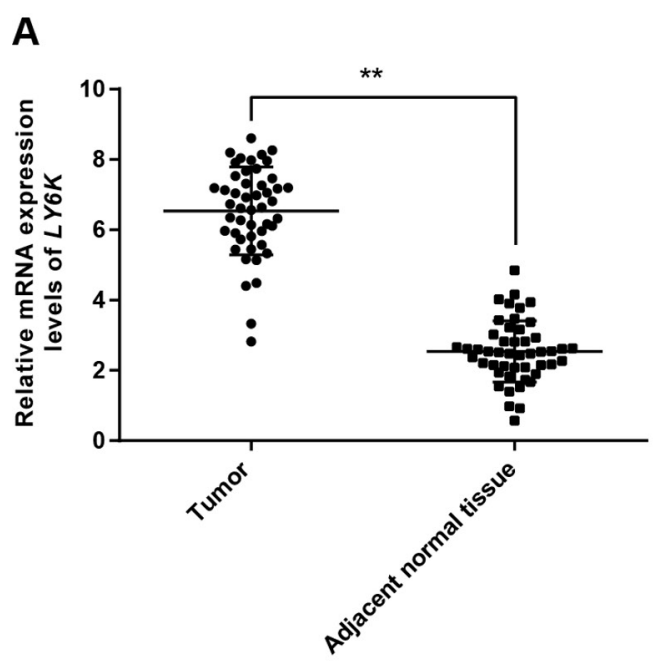

B

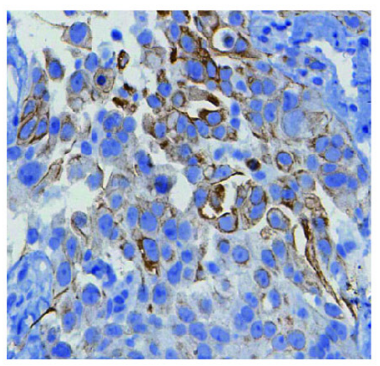

Tumor

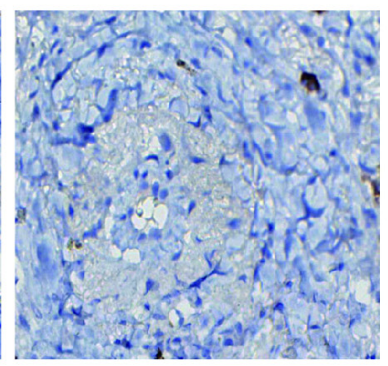

Paired adjacent normal tissues

Figure 2. LY6K is highly expressed in NSCLC. A) Relative expression of $L Y 6 K \mathrm{mRNA}$ in tumor tissues and paired adjacent normal tissues. The results were normalized to GAPDH mRNA expression and expressed as fold change in tumor compared to paired adjacent normal tissues. B) Imunohistochemical stain in patterns of $L Y 6 K$ in matched NSCLC and adjacent non-tumor tissues. ${ }^{* *} \mathbf{p}<0.001$.

A

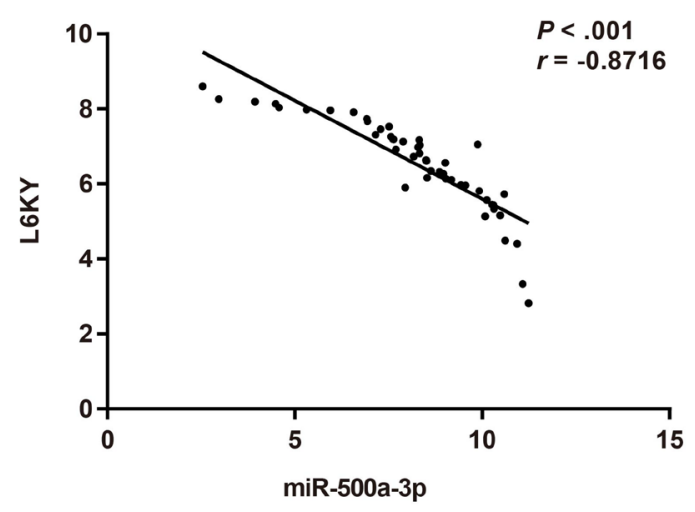

C

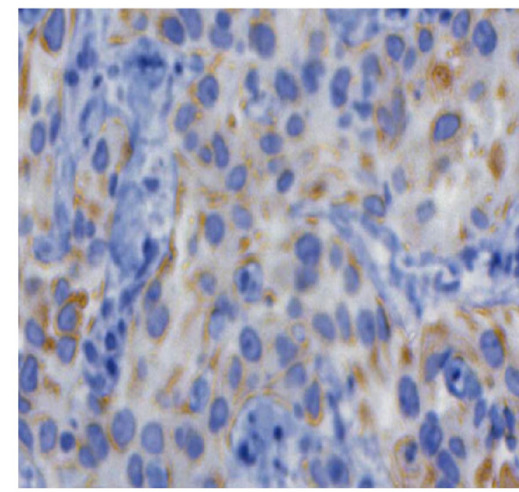

Low miR-500a-3p expression group
B
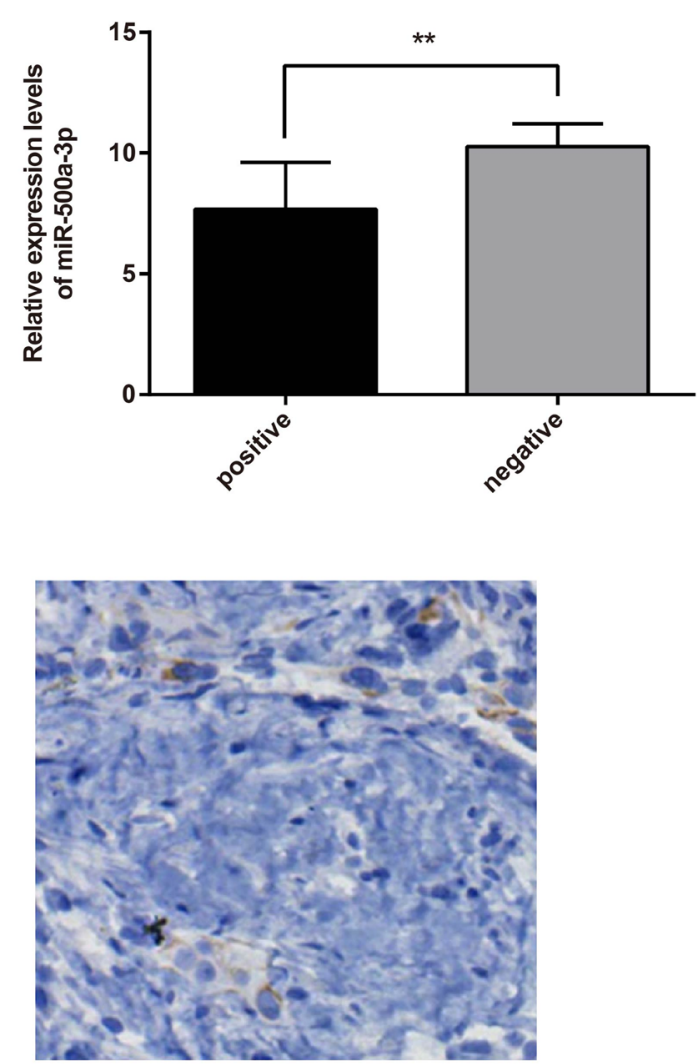

High miR-500a-3p expression group

Figure 3. The expression of miR-500a-3p was negatively correlated with the expression of $L Y 6 K$ inNSCLC. A) Inverse correlation between $L Y 6 K$ mRNA and miR-500a-3p in NSCLC tisues. The analysis was performed by Pearson' correlation test. B) The histogram shows the expression of $L Y 6 K$ protein level and miR-500a-3p in NSCLC. C) Immunohistochemical stain in patterns of $L Y 6 \mathrm{~K}$ between low and high miR-500a-3p expression groups. The $L Y 6 \mathrm{~K}$ protein level was detected by immunohistochemistry and the mRNA expression by $\mathrm{qRT}-\mathrm{PCR} .{ }^{* *} \mathrm{p}<0.001$. 


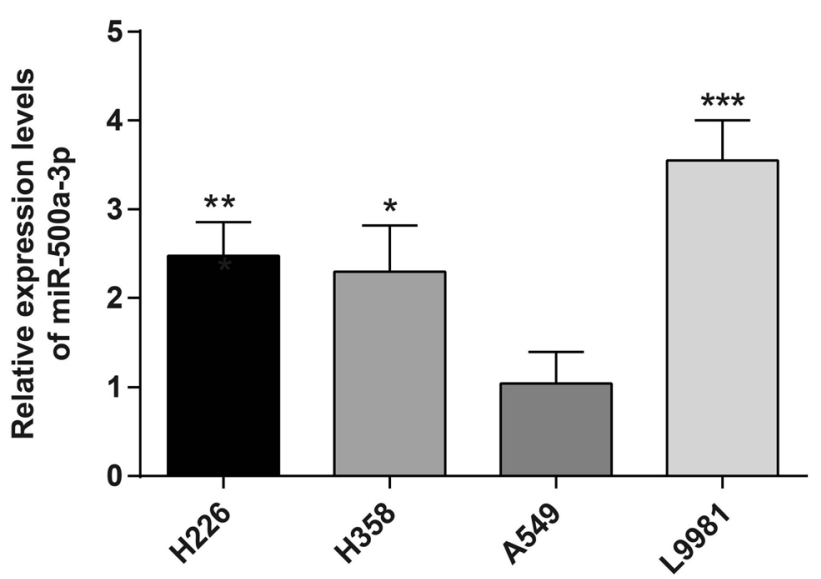

Figure 4. Screening of NSCLC cell lines with low expression of miR-500a3 p. Expression level of miR-500a-3p in four NSCLC cell lines (H226, H358, A549 and L9981) was detected by qrt-PCR, finding that the expression level of miR-500a-3p in $\mathrm{H} 226, \mathrm{H} 358$ cells were stable. ${ }^{*} \mathrm{p}<0.05$ vs. A549, ${ }^{* *} \mathrm{p}<0.01$ vs. A549, ${ }^{* * *} \mathrm{p}<0.001$ vs. A549.

Table 2. The relationship between LY6K expression level and clinical pathological characteristics of NSCLC patients.

\begin{tabular}{|c|c|c|c|c|c|}
\hline \multirow{2}{*}{$\begin{array}{l}\text { Clinical character- } \\
\text { istics }\end{array}$} & \multirow{2}{*}{$\begin{array}{l}\text { No. of } \\
\text { cases }\end{array}$} & \multicolumn{2}{|c|}{ LY6K } & \multirow{2}{*}{$\begin{array}{l}\text { Positive } \\
\text { rate }(\%)\end{array}$} & \multirow{2}{*}{ p-value } \\
\hline & & Positive & Negative & & \\
\hline Age & & & & & 0.08 \\
\hline$<60$ & 26 & 23 & 3 & 68.2 & \\
\hline$\geq 60$ & 22 & 15 & 7 & 88.5 & \\
\hline Gender & & & & & 0.23 \\
\hline Male & 35 & 28 & 7 & 80.0 & \\
\hline Female & 13 & 10 & 3 & 76.9 & \\
\hline Tumor site & & & & & 0.65 \\
\hline Left & 21 & 16 & 5 & 76.2 & \\
\hline Right & 27 & 22 & 5 & 81.5 & \\
\hline Tumor differentiation & & & & & 0.02 \\
\hline Low & 28 & 19 & 9 & 67.9 & \\
\hline High/moderate & 20 & 19 & 1 & 95 & \\
\hline Primary tumor lesions & & & & & 0.52 \\
\hline $\mathrm{T} 1$ & 40 & 31 & 9 & 77.5 & \\
\hline $\mathrm{T} 2$ & 8 & 7 & 1 & 87.5 & \\
\hline \multicolumn{2}{|c|}{ Regional lymph node metastasis } & & & & 0.02 \\
\hline $\mathrm{N} 0 / \mathrm{N} 1$ & 25 & 23 & 2 & 65.2 & \\
\hline $\mathrm{N} 2 / \mathrm{N} 3$ & 23 & 15 & 8 & 92 & \\
\hline TNM stage & & & & & $<0.02$ \\
\hline $\mathrm{I} / \mathrm{II}$ & 21 & 13 & 8 & 61.9 & \\
\hline III/IV & 27 & 25 & 2 & 92.6 & \\
\hline Histology & & & & & 0.58 \\
\hline Adenocarcinoma & 30 & 23 & 7 & 76.7 & \\
\hline Squamous and others & 18 & 15 & 3 & 83.3 & \\
\hline
\end{tabular}

NSCLC, non-small cell lung cancer; TNM, tumor, node, and metastasis

lish the role of miR-500a-3p in negatively targeting $L Y 6 K$ in NSCLC cell proliferation and invasion. Cell lines were divided into inhibitors, inhibitors + si-LY6K group and control inhibitors.
Figure 6A highlights that CCK8 assay at 24, 48 and 72 hours determined that cells grew significantly faster in the inhibitors group than for control inhibitors; and at 48 and 72 hours, the inhibitor group grew significantly faster than inhibitors + si-LY6K and control inhibitors groups (all $\mathrm{p}<0.05$ ). This suggests that $L Y 6 K$ silencing by siRNA inhibits the miR-500a-3p promotion role in cell growth. The Transwell invasion assay then showed that the inhibitors group had a significant larger number of invasive cells than either the control inhibitor or inhibitors + si- $L Y 6 K$ groups (Figure 6B - all $\mathrm{p}<0.05$ ). This indicates that miR-500a-3p suppression enhances NSCLC cell invasion while $L Y 6 K$ silencing by siRNA inhibits miR-500a-3p from accelerating cell invasion (all $\mathrm{p}<0.05)$. These results enhance the conclusion that miR-500a-3p inhibition of $L Y 6 K$ reduces NSCLC cell proliferation and invasion.

MiR-500a-3p targeting LY6K suppresses the in vivo tumorigenesis of NSCLC cells. Experimental mice were humanely sacrificed 8 weeks after transfection. The transplanted tumors were excised and sizes in the different groups compared. The inhibitors group with miR-500a-3p suppression had faster tumorigenesis than control inhibitors group and inhibitors + si-LY6K group (all $\mathrm{p}<0.05$ ), and there was no significant difference between the inhibitors + si-LY6K and inhibitors groups (all $\mathrm{p}>0.05$ ) (Figure 7A, B). Again, results infer that miR-500a-3p inhibition of LY6K suppresses NSCLC cell proliferation in vivo.

Based on study findings, it is evident that down-regulation of miR-500a-3p is a promoter of NSCLC cell proliferation and invasion; partly through the induction of LY6K. It is therefore safe to conclude that miR-500a-3p targeting $L Y 6 K$ is involved in NSCLC progression, and miR-500a-3p can therefore provide novel therapy in NSCLC.

\section{Discussion}

Recent studies have reported aberrantly expressed miRNAs in various human tumors [17]. Since miRNAs can act as oncogenes or tumor suppressors through regulation on its target genes, it is critical to understand the roles of miRNAs in tumorigenesis; and this is important in establishing novel therapeutic targets $[18,19]$.

Our study determined that miR-500a-3p was downregulated in NSCLC tumor tissues and significantly correlates with tumor differentiation, lymph node metastasis and TNM staging. Therefore, reduced miR-500a-3p could be a promoter for NSCLC development and a useful biomarker in diagnosis and prognosis. There is evidence that miR-500a-3p correlates with poor response to therapy in patients with breast cancer [15]. Meanwhile, miR-500a-3p in ERa-negative breast cancer cells can be increased by ERa, and re-expressing miR-500a-3p could be a potential therapeutic approach for treating tamoxifen resistant patients [16]. Although some studies have reported that miR-500a was up-regulated in human cancers such as hepatocellular carcinoma and chronic 
A

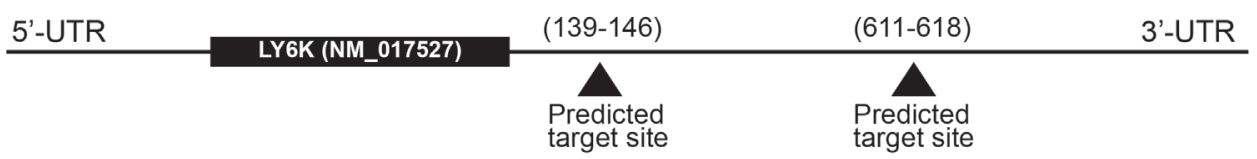

\begin{tabular}{|c|c|c|c|}
\hline hsa-miR-500a-3p & 3'-GUCUUAGGAACGGGUCCACGUA-5' & hsa-miR-500a-3p & 3'-GUCUUAGGAACGGGUCCACGUA-5' \\
\hline $\begin{array}{c}\text { LY6K 3'UTR WT } \\
\text { site } 1\end{array}$ & 5'-GGAGAGUGGGGAUCAGGUGCAG-3' & $\begin{array}{c}\text { LY6K 3'UTR WT } \\
\text { site } 2\end{array}$ & 5'-CCACCAGCUGGCACAGGUGCAC-3' \\
\hline $\begin{array}{c}\text { LY6K 3'UTR MT } \\
\text { site } 1\end{array}$ & 5'-GGAGAGUGGGGAUCAGACGUAG-3' & $\begin{array}{c}\text { LY6K 3'UTR MT } \\
\text { site } 2\end{array}$ & 5'-CCACCAGCUGGCACAGACTCAC-3' \\
\hline
\end{tabular}

B
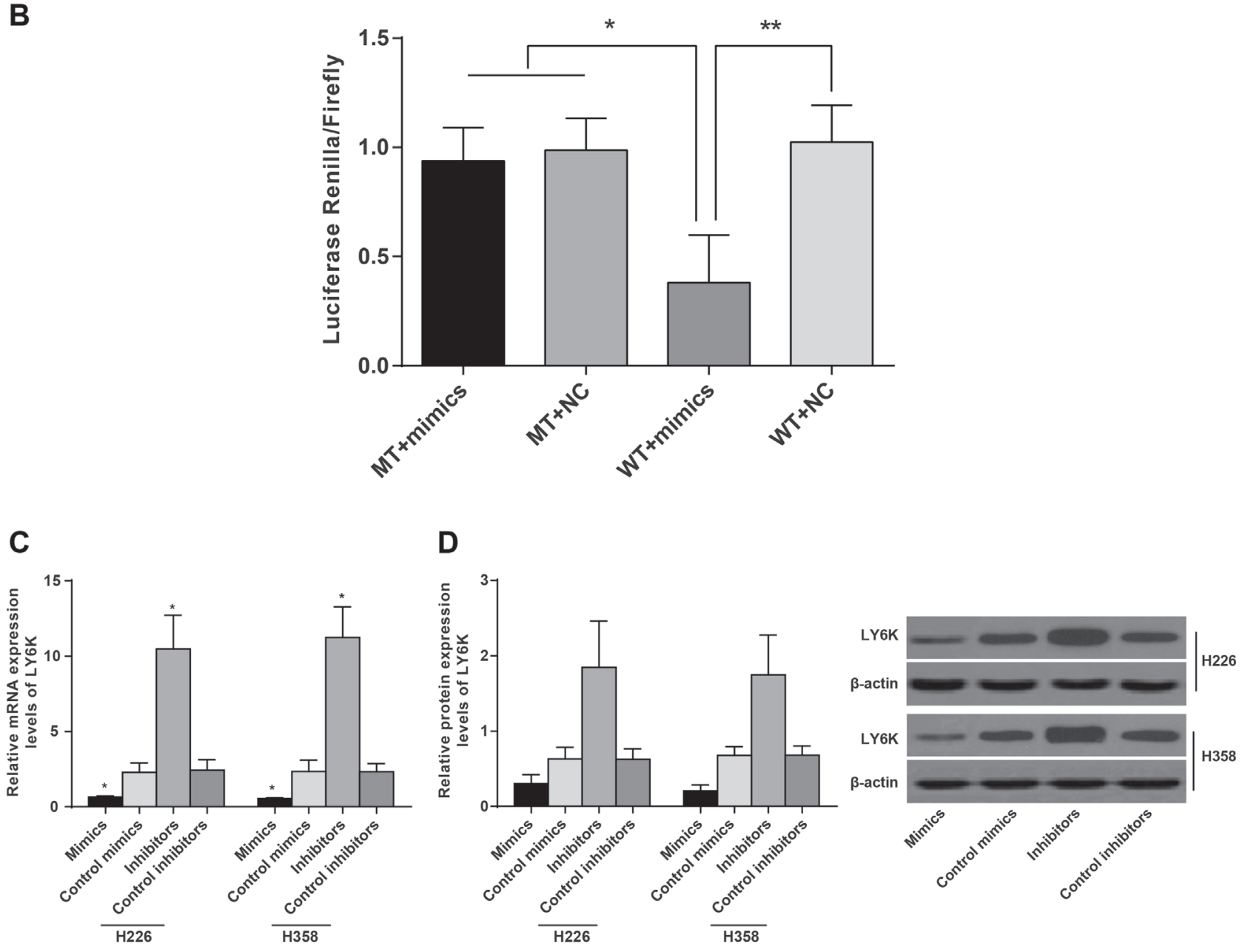

Figure 5. miR-500a-3p suppressed LY6K expression by binding to the LY6K-3'UTR. A) Schematic description of the LY6K-3'UTR with putative binding sites for miR-500a-3p. The triangles indicate the mutant nucleotides. B) Luciferase reported plasmids containing the wt or mutant LY6K-3'UTR was co-transfected into $293 \mathrm{~T}$ cells with miR-500a-3p mimics and the negative control. After transfection for 36 hours, the luciferase activity was measured. It was found that miR-500a-3p inhibited wt, but not mutant, LY6K-3'UTR reporter activity. C) qRT-PCR analysis of $L Y 6 K$ mRNA in cells transfected with miR-500a-3p mimics, Control mimics, miR-500a-3p inhibitors and Control inhibitors in $\mathrm{H} 226$ and $\mathrm{H} 358$ cell lines. The results were normalized to GAPDH mRNA expression. D) LY6K protein levels in cells transfected with miR-500a-3p mimics, Control mimics, miR-500a-3p inhibitors, Control inhibitors groups were also detected by western blot and standardized to $\beta$-actin protein. Bar graph represents quantization of protein level (left). ${ }^{*} \mathrm{p}<0.05 ;{ }^{* *} \mathrm{p}<0.01$. All data are representative of three independent experiments. 
lymphocytic cancer [21], little is known about miR-500a-3p's precise activity and the only existing studies suggest that miR-500a-3p can be increased or decreased in the progression of different tumors and promote or suppress tumor growth. Our study therefore has certain clinical significance.

The glycosylphosphatidylinositol-anchoring signal sequence reveals that LY6K can have two types of proteins; glycosylphosphatidylinositol-anchored transmembrane proteins and secretory protein without a glycosylphosphatidylinositol-anchoring signal sequence [22]. The glycosylphosphatidylinositol-anchored proteins participate in tumor invasion, growth and metastasis via the integrinrelated Ras/ERK signaling pathway [23-25]. There is increasing evidence of elevated expression of LY6K mRNA in malignancies such as head and neck squamous cell carcinoma and breast, lung and bladder cancers $[6,26,27]$. Further, qRT-PCR and Western Blot assay determined that LY6K was significantly up-regulated in NSCLC and related to the clinical-pathological features. Meanwhile, miR-500a-3p negatively correlated with $L Y 6 K$ in selected NSCLC cell lines, both in mRNA expression and protein expression, thus suggesting it directly targets $L Y 6 \mathrm{~K}$. This interaction between miR-500a-3p and LY6K was further confirmed by the dualluciferase reporter assay.

These findings inspired us to verify the impact of miR-500a-3p on proliferation and invasion of NSCLC cell
A

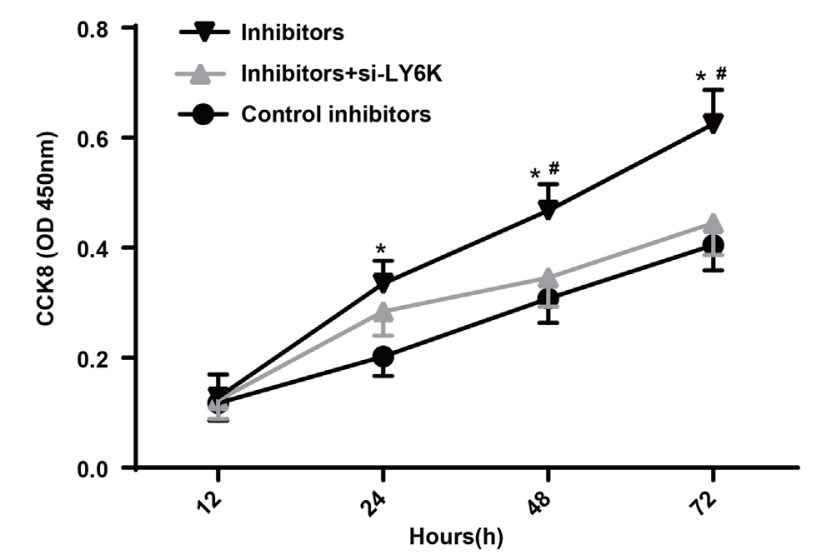

B
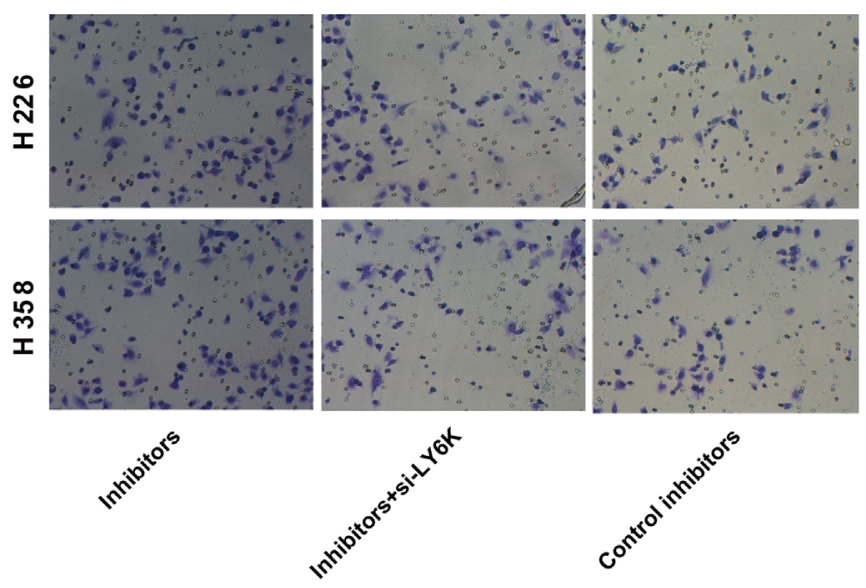

H358 cell
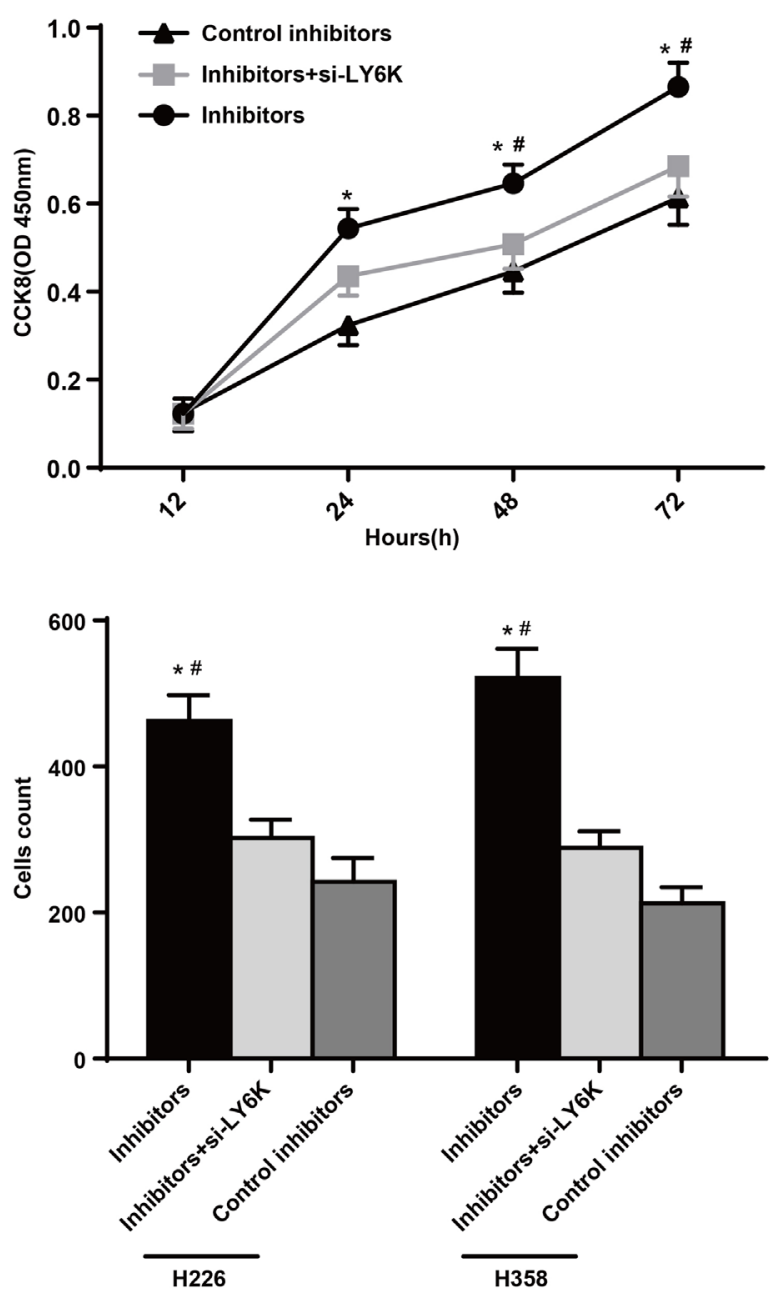

Figure 6. miR-500a-3p inhibiting LY6K may weaken the proliferation and invasion of NSCLC cells. A) CCK8 assay was conducted to observe cell growth of $\mathrm{H} 226$ and $\mathrm{H} 358$ cell lines in Inhibitors group, Inhibitors $+\mathrm{si}-\mathrm{LY} 6 \mathrm{~K}$ group and Control inhibitors group. It was observed that, at $24 \mathrm{~h}, 48 \mathrm{~h}$ and $72 \mathrm{~h}$, Inhibitors presented faster cell growth than Control inhibitors group; at $48 \mathrm{~h}$ and $72 \mathrm{~h}$, Inhibitors presented faster cell growth than Inhibitors + si- $L Y 6 \mathrm{~K}$ group, and the difference is significant. B) Transwell invasion assay was performed to inspect cell invasion of $\mathrm{H} 226$ and $\mathrm{H} 358$ cell lines in Inhibitors group, Inhibitors + si- LY6K group and Control inhibitors $(200 \times)$, with the finding that the Inhibitors group had a significantly larger number of invasive cells than the Control inhibitors and Inhibitors $+s i-L Y 6 K$ groups. All data are representative of three independent experiments. ${ }^{*} p<0.05$ (vs. Control inhibitors group), ${ }^{*} \mathrm{p}<0.05$ (vs. Inhibitors + si- $L Y 6 K$ group). 
A

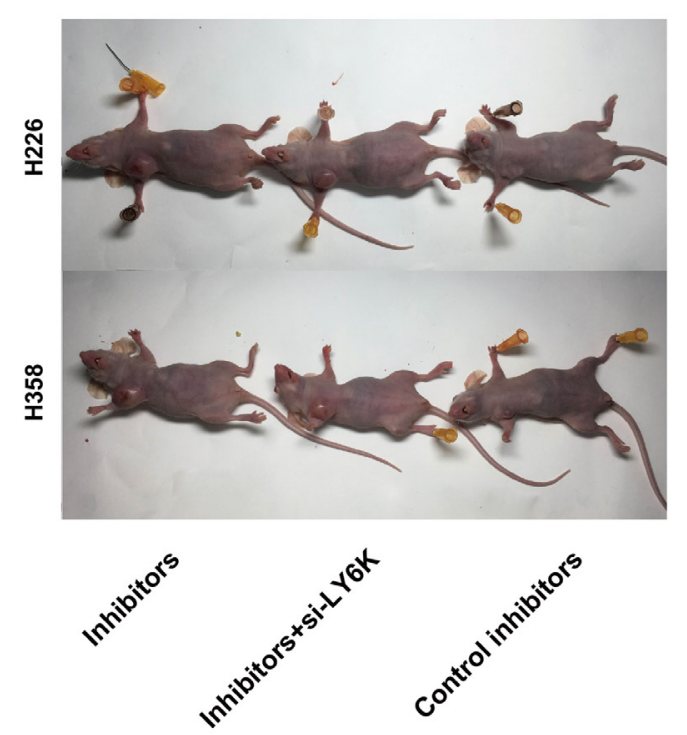

B

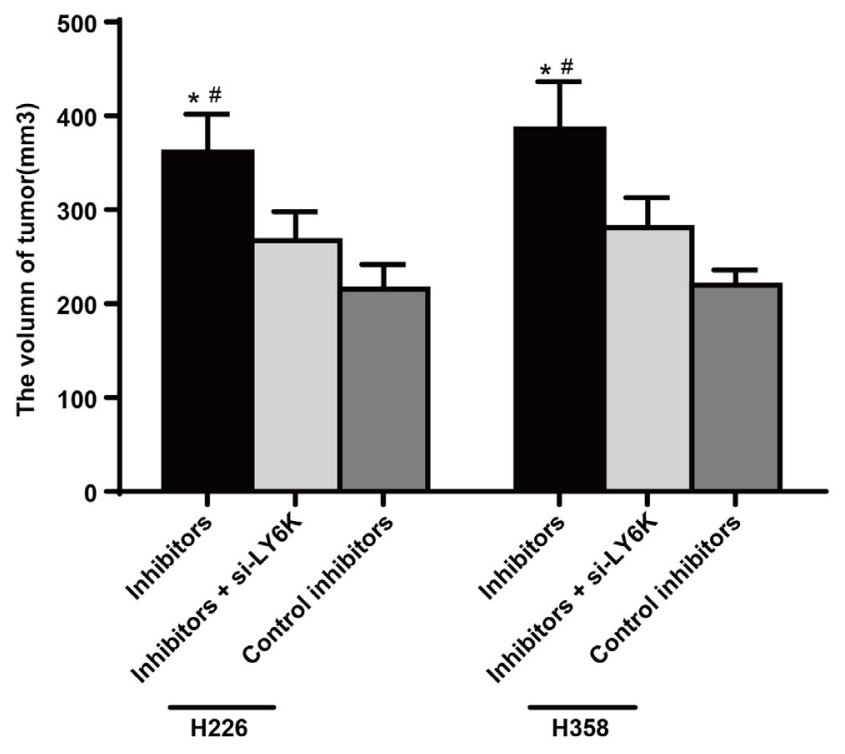

Figure 7. miR-500a-3p targeting LY6K suppresses the in vivo tumorigenesis of NSCLC cells. A) Representative photo of a mouse lung with H226 or H358 cells which contain the miR-500a-3p inhibitors or LY6K siRNA or negative control sequence; B) Volumetric comparison of the orthotropic transplantation tumors between the groups; All data are representative of three independent experiments. ${ }^{*} \mathrm{p}<0.05$ (vs. Control inhibitors group), ${ }^{\#} \mathrm{p}<0.05$ (vs. Inhibitors + si-LY6K group).

lines. Our results established that inhibition of miR-500a-3p promoted cell proliferation, but its function was obviously weakened by $L Y 6 K$ silencing. Similarly, a previous study showed that LY6K knockdown remarkably suppressed growth of lung and esophageal cancer cells [6].

Previous researchers support our work in their illustration that LY6K over-expression in xenograft tumors is associated with distant metastasis and survival rate, and that $L Y 6 K$ knockdown significantly slows tumor development [28]. Studies also show that $L Y 6 K$ promotes aggressive features in NSCLC and ESCC and that it is therefore a promising therapeutic target at the molecular level [6]. We therefore believe that $L Y 6 K$ is a promoter factor in NSCLC progression.

Reduced miR-500a-3p in targeting LY6K can contribute to NSCLC development. We therefore constructed an animal model of NSCLC which identified that transplanted tumors in mice with suppressed miR-500a-3p are significantly larger than those in mice with suppressed miR-500a-3p and silenced LY6K. This clearly suggests that miR-500a-3p targeting LY6K is involved in tumorigenesis in vivo, and despite the rigorous evidence our study has provided, bias may exist from undefined detailed mechanisms of miR-500a-3p/LY6K interaction and therefore further study is recommended.

Finally, our study clearly established that miR-500a-3p was decreased in NSCLC tissues and cell lines, and that increased expression of miR-500a-3p inhibited NSCLC cell proliferation and invasion. The tumor anti-oncogenes function of miR-500a-3p was mediated by down-regulation of its downstream LY6K target gene. While pre-clinical studies are required to confirm miR-500a-3p's clinical usefulness, our findings demonstrate that it should certainly be considered a potential therapeutic target in Non Small Cell Lung Cancer.

\section{References}

[1] SIEGEL RL, MILLER KD, JEMAL A. Cancer statistics, 2016. CA Cancer J Clin 2016; 66: 7-30. https://doi.org/10.3322/ caac. 21332

[2] D'ARCANGELO M, HIRSCH FR. Clinical and comparative utility of afatinib in non-small cell lung cancer. Biologics 2014; 8: 183-192. https://doi.org/10.2147/BTT.S40567

[3] TRAVIS WD. Pathology of lung cancer. Clin Chest Med 2011; 32: 669-692. https://doi.org/10.1016/j. ccm.2011.08.005

[4] JEMAL A, SIEGEL R, XU J, WARD E. Cancer statistics, 2010. CA Cancer J Clin 2010; 60: 277-300. https://doi. org/10.3322/caac.20073

[5] BRAKENHOFF RH, GERRETSEN M, KNIPPELS EM, VAN DIJK M, VAN ESSEN H et al. The human E48 antigen, highly homologous to the murine Ly-6 antigen ThB, is a GPI-anchored molecule apparently involved in keratinocyte cell-cell adhesion. J Cell Biol 1995; 129: 1677-1689. 
[6] ISHIKAWAN, TAKANO A, YASUIW, INAIK, NISHIMURA

$\mathrm{H}$ et al. Cancer-testis antigen lymphocyte antigen 6 complex locus $\mathrm{K}$ is a serologic biomarker and a therapeutic target for lung and esophageal carcinomas. Cancer Res 2007; 67: 1160111611. https://doi.org/10.1158/0008-5472.CAN-07-3243

[7] COFFRE M, KORALOV SB. miRNAs in B Cell Development and Lymphomagenesis. Trends Mol Med 2017; 23: 721-736. https://doi.org/10.1016/j.molmed.2017.06.001

[8] STAHLHUT C, SLACK FJ. Combinatorial Action of MicroRNAs let-7 and miR-34 Effectively Synergizes with Erlotinib to Suppress Non-small Cell Lung Cancer Cell Proliferation. Cell Cycle 2015; 14: 2171-2180. https://doi.org/10.1080 /15384101.2014.1003008

[9] SALIM H, AKBAR NS, ZONG D, VACULOVA AH, LEWENSOHN R et al. miRNA-214 modulates radiotherapy response of non-small cell lung cancer cells through regulation of p38MAPK, apoptosis and senescence. Br J Cancer 2012; 107: 1361-1373. https://doi.org/10.1038/bjc.2012.382

[10] XIN H, JIANG D, LU Z, SUN S, KONG J et al. [Effect of miRNA-135b on proliferation, invasion and migration of triple-negative breast cancer by targeting APC]. Zhonghua Yi Xue Za Zhi 2015; 95: 2474-2477.

[11] LIN Z, SONG D, WEI H, YANG X, LIU T et al. TGF-beta1-induced miR-202 mediates drug resistance by inhibiting apoptosis in human osteosarcoma. J Cancer Res Clin Oncol 2016; 142: 239-246. https://doi.org/10.1007/s00432-0152028-9

[12] SUH SS, YOO JY, CUI R, KAUR B, HUEBNER K et al. FHIT suppresses epithelial-mesenchymal transition (EMT) and metastasis in lung cancer through modulation of microRNAs. PLoS Genet 2014; 10: e1004652. https://doi. org/10.1371/journal.pgen.1004652

[13] WANG Y, XU L, JIANG L. miR-1271 promotes non-smallcell lung cancer cell proliferation and invasion via targeting HOXA5. Biochem Biophys Res Commun 2015; 458: 714719. https://doi.org/10.1016/j.bbrc.2015.02.033

[14] XIE X, LIU H, WANG M, DING F, XIAO H et al. miR-342$3 p$ targets RAP2B to suppress proliferation and invasion of non-small cell lung cancer cells. Tumour Biol 2015; 36: 5031-5038. https://doi.org/10.1007/s13277-015-3154-3

[15] REVATHIDEVI S, SUDESH R, VAISHNAVI V, KALIYANASUNDARAM M, MARYHELEN KG et al. Screening for the 3'UTR Polymorphism of the PXR Gene in South Indian Breast Cancer Patients and its Potential Role in Pharmacogenomics. Asian Pac J Cancer Prev 2016; 17: 3971-3977.

[16] KIM YS, PARK SJ, LEE YS, KONG HK, PARK JH. miRNAs involved in LY6K and estrogen receptor alpha contribute to tamoxifen-susceptibility in breast cancer. Oncotarget 2016; 7: 42261-42273. https://doi.org/10.18632/oncotarget.9950

[17] DI LEVA G, CROCE CM. Roles of small RNAs in tumor formation. Trends Mol Med 2010; 16: 257-267. https://doi. org/10.1016/j.molmed.2010.04.001
[18] ZHAO Q, LI P, MA J, YU X. MicroRNAs in Lung Cancer and Lung Cancer Bone Metastases: Biomarkers for Early Diagnosis and Targets for Treatment. Recent Pat Anticancer Drug Discov 2015; 10: 182-200.

[19] LU J, GETZ G, MISKA EA, ALVAREZ-SAAVEDRA E, LAMB J et al. MicroRNA expression profiles classify human cancers. Nature 2005; 435: 834-838. https://doi.org/10.1038/ nature 03702

[20] JIANG C, LONG J, LIU B, XU M, WANG W et al. miR-500a$3 p$ promotes cancer stem cells properties via STAT3 pathway in human hepatocellular carcinoma. J Exp Clin Cancer Res 2017; 36: 99. https://doi.org/10.1186/s13046-017-0568-3

[21] RUIZ-LAFUENTE N, ALCARAZ-GARCIA MJ, SEBASTIAN-RUIZ S, GARCIA-SERNA AM, GÓMEZ-ESPUCH J et al. IL-4 Up-Regulates MiR-21 and the MiRNAs Hosted in the CLCN5 Gene in Chronic Lymphocytic Leukemia. PLoS One 2015; 10: e0124936. https://doi.org/10.1371/journal. pone.0124936

[22] KONG HK, YOON S, PARK JH. The regulatory mechanism of the LY6K gene expression in human breast cancer cells. J Biol Chem 2012; 287: 38889-38900. https://doi.org/10.1074/ jbc.M112.394270

[23] SAWAI H, OKADA Y, FUNAHASHI H, MATSUO Y, TAKAHASHI $\mathrm{H}$ et al. Interleukin-1alpha enhances the aggressive behavior of pancreatic cancer cells by regulating the alpha6beta1-integrin and urokinase plasminogen activator receptor expression. BMC Cell Biol 2006; 7: 8. https://doi. org/10.1186/1471-2121-7-8

[24] PLOUG M, ELLIS V. Structure-function relationships in the receptor for urokinase-type plasminogen activator. Comparison to other members of the Ly- 6 family and snake venom alpha-neurotoxins. FEBS Lett 1994; 349: 163-168.

[25] DE NOOIJ-VAN DALEN AG, VAN DONGEN GA, SMEETS SJ, NIEUWENHUIS EJ, STIGTER-VAN WALSUM $M$ et al. Characterization of the human Ly-6 antigens, the newly annotated member Ly-6K included, as molecular markers for head-and-neck squamous cell carcinoma. Int J Cancer 2003; 103: 768-774. https://doi.org/10.1002/ijc.10903

[26] LEE JW, LEE YS, YOO KH, LEE KH, PARK K et al. LY-6K gene: a novel molecular marker for human breast cancer. Oncol Rep 2006; 16: 1211-1214.

[27] MATSUDA R, ENOKIDA H, CHIYOMARU T, KIKKAWA $\mathrm{N}$, SUGIMOTO $\mathrm{T}$ et al. LY6K is a novel molecular target in bladder cancer on basis of integrate genome-wide profiling. Br J Cancer 2011; 104: 376-386. https://doi.org/10.1038/ sj.bjc. 6605990

[28] KONG HK, PARK SJ, KIM YS, KIM KM, LEE HW et al. Epigenetic activation of LY6K predicts the presence of metastasis and poor prognosis in breast carcinoma. Oncotarget 2016; 7: 55677-55689. https://doi.org/10.18632/oncotarget. 10972 